\title{
Impulsivity and compulsivity in Internet gaming disorder: A comparison with obsessive-compulsive disorder and alcohol use disorder
}

\author{
YEON-JIN KIM ${ }^{1}$, JAE A. LIM ${ }^{1}$, JI YOON LEE ${ }^{1,2}$, SOHEE OH ${ }^{3}$, SUNG NYUN KIM ${ }^{4}$, DAI JIN KIM ${ }^{5}$, JONG EUN HA ${ }^{6}$, \\ JUN SOO KWON ${ }^{2,7}$ and JUNG-SEOK CHOI ${ }^{1,7 *}$ \\ ${ }^{1}$ Department of Psychiatry, SMG-SNU Boramae Medical Center, Seoul, Republic of Korea \\ ${ }^{2}$ Department of Brain and Cognitive Sciences, College of Natural Sciences, Seoul National University, Seoul, Republic of Korea \\ ${ }^{3}$ Department of Biostatistics, SMG-SNU Boramae Medical Center, Seoul, Republic of Korea \\ ${ }^{4}$ Department of Psychiatry, SMC - Seoul Medical Center, Seoul, Republic of Korea \\ ${ }^{5}$ Department of Psychiatry, Seoul St. Mary's Hospital, College of Medicine, The Catholic University of Korea, Seoul, \\ Republic of Korea \\ ${ }^{6}$ Department of Psychiatry, Alcohol Treatment Center, KARF St. Mary's Hospital, Goyang, Gyeonggi-do, Republic of Korea \\ ${ }^{7}$ Department of Psychiatry, College of Medicine, Seoul National University, Seoul, Republic of Korea
}

(Received: July 18, 2017; revised manuscript received: September 2, 2017; accepted: October 1, 2017)

\begin{abstract}
Background and aims: Internet gaming disorder (IGD) is characterized by a loss of control and a preoccupation with Internet games leading to repetitive behavior. We aimed to compare the baseline neuropsychological profiles in IGD, alcohol use disorder (AUD), and obsessive-compulsive disorder (OCD) in the spectrum of impulsivity and compulsivity. Methods: A total of 225 subjects (IGD, $N=86$; AUD, $N=39$; OCD, $N=23$; healthy controls, $N=77$ ) were administered traditional neuropsychological tests including Korean version of the Stroop Color-Word test and computerized neuropsychological tests, including the stop signal test (SST) and the intra-extra dimensional set shift test (IED). Results: Within the domain of impulsivity, the IGD and OCD groups made significantly more direction errors in SST $(p=.003, p=.001)$ and showed significantly delayed reaction times in the color-word reading condition of the Stroop test $(p=.049, p=.001)$. The OCD group showed the slowest reading time in the color-word condition among the four groups. Within the domain of compulsivity, IGD patients showed the worst performance in IED total trials measuring attentional set shifting ability among the groups. Conclusions: Both the IGD and OCD groups shared impairment in inhibitory control functions as well as cognitive inflexibility. Neurocognitive dysfunction in IGD is linked to feature of impulsivity and compulsivity of behavioral addiction rather than impulse dyscontrol by itself.
\end{abstract}

Keywords: behavioral addiction, compulsivity, Internet gaming disorder, impulsivity, obsessive-compulsive disorder

\section{INTRODUCTION}

Internet gaming disorder (IGD) was recently included in the fifth edition of the Diagnostic and Statistical Manual of Mental disorders (DSM-5) as "a condition for further study." The clinical diagnosis of IGD is based on behavioral patterns encompassing persistent thoughts about Internet games and persistent use of the Internet to engage in games, leading to significant impairment or distress (American Psychiatric Association, 2013). Symptoms in patients with IGD resemble addiction-specific phenomena, comparable with those seen in substance-related addiction, including cravings and withdrawal symptoms such as unpleasant feeling states, and tolerance. Consistent with this notion, many researchers have proposed that IGD be recognized as a behavioral addiction (Dowling, 2014; Pontes, Kiraly, Demetrovics, \& Griffiths, 2014). There have been suggested the needs for establishing diagnostic criteria of IGD as a form of unique condition, differentiating from substance use or gambling disorder (Griffiths et al., 2016). Moreover, debates on the proposed inclusion of gaming disorder in the upcoming ICD-11 have been included in the specificity of current operationalization of the IGD construct compared with other traditional substance addiction (Aarseth et al., 2017). In spite of such concerns, other researchers claim that loss of control and continued playing behavior despite negative consequences of gaming disorder in ICD-11 proposal have strong general support and would fit well in behavioral addiction framework. Both DSM-5 and ICD-11 proposal have loss of control and continuous harmful behavior in common, as definite features of IGD (Király \& Demetrovics, 2017). Hence, great attention would be paid to integrate the neurobiological substrate and clinical phenomenon of loss of control and repetitive behavior in the direction of alternative theoretical models.

\footnotetext{
* Corresponding author: Jung-Seok Choi, MD, PhD; Department of Psychiatry, SMG-SNU Boramae Medical Center, 20, Boramae-Ro 5-Gil, Dongjak-Gu, Seoul 07061, Republic of Korea; Phone: +82 2 870 3461; Fax: +82 2744 7241; E-mail: choijs73@gmail.com
} 
Alcohol use disorder (AUD), a "traditional" substance addictive disorder, shows repeated behavior involving continued excessive use of the substance (Hyman, 2007). Obsessive-compulsive disorder (OCD) is also associated with repetitive compulsive behavior. Most patients with OCD have excessive repetitive behavior, characterized by an inability to delay or inhibit ongoing action, leading to functional impairment (Gillan et al., 2011).

IGD and substance use disorder (SUD) have some phenomenological overlap with OCD in terms of repetitive behaviors. A feature of IGD involves repeated unsuccessful efforts to control gaming behavior. Similarly, patients with SUD cannot resist their impulse toward substance use and continue compulsive substance consumption despite adverse consequences (O’Brien, Volkow, \& Li, 2006).

Such phenomenological similarities across these disorders in terms of repetitive behavior can be viewed in terms of the spectrum between impulsivity and compulsivity. Traditionally, impulsivity and compulsivity have been proposed as opposite constructs. The impulsivity construct is conceptualized as a tendency to act prematurely without foresight, in a manner that is unduly risky or inappropriate to the situation, whereas compulsivity is related to repetitive behaviors in a habitual manner to protect the individual from perceived negative consequences (Curatolo, Paloscia, D’Agati, Moavero, \& Pasini, 2009; Menzies et al., 2007).

However, regarding symptoms, disorders characterized by impulsivity often share features with compulsivity (Grant \& Kim, 2014). Indeed, it has been proposed that impulsive and compulsive behaviors overlap and often become more intertwined over time. In attempting to understand the neurobiological and psychological processes mediating addictive behavior, researchers have suggested that continued substance use is not only related to an intense urge and craving but also to loss of control and a compulsive pattern (Altman et al., 1996). Patients with OCD have difficulty suppressing intrusive thoughts, and their compulsive behavior might arise from such an underlying deficit in inhibitory cognitive control (Purcell, Maruff, Kyrios, \& Pantelis, 1998).

On a neuroanatomical level, these two constructs may both be explained by a failure of the response-control system mediated by separate but intercommunicating frontal-striatal neural circuits (Dalley, Everitt, \& Robbins, 2011). On a neurocognitive level, obsessive-compulsive symptoms seen in OCD have been suggested to result from a failure of inhibitory control or inability to shift attention from these ongoing thoughts or motor activities toward less distressing ones (Greisberg \& McKay, 2003). Furthermore, many studies have examined cognitive dysfunction in OCD based on the assumption that compulsive behaviors result from failure of dysfunctional frontal circuits to inhibit basal ganglia motor or cognitive programs (Okasha et al., 2000). In an attempt to understand OCD within this impulsivecompulsive spectrum, a previous study proposed that impulsive and compulsive symptoms in OCD refer to cognitive inflexibility as well as impaired motor inhibition based on cognitive tasks assessing the ability to shift attentional focus and to suppress unwanted motor responses (Chamberlain, Fineberg, Blackwell, Robbins, \& Sahakian, 2006). The author also reported that OCD patients showed cognitive inflexibility, as measured by extradimensional set shifting and motor impulsivity using stop signal reaction time (Chamberlain et al., 2006).

To investigate disrupted underlying neurocognitive processes across behavioral addiction, substance addiction, and OCD, a recent study directly compared pathological gambling (PG), alcohol dependence (AD), and OCD patients with healthy controls (HC) on self-reported and cognitive measures of compulsivity and impulsivity (Bottesi, Ghisi, Ouimet, Tira, \& Sanavio, 2015). They suggested similarities and differences in patterns across $\mathrm{PG}, \mathrm{AD}$, and OCD groups in motor inhibition ability and decision-making processes (Bottesi et al., 2015). In a recent study, directly comparing impulsivity and compulsivity in IGD, PG, and AUD patients using neurocognitive measurements, the IGD group was found to share features of impulsivity rather than compulsivity with those having other addictive disorders (Choi, Kim, et al., 2014). Taken together, a recent review raises issues of direct comparison of IGD and OCD at a neurobiological level to provide more precise conceptualization of IGD between behavioral addiction and impulse-control disorders as initial impulsivity followed by compulsivity in behavioral addiction can be differentiated from impulsecontrol disorder (Starcevic \& Aboujaoude, 2017).

In this study, our objective was to investigate two questions: (i) whether IGD patients exhibit higher disinhibition compared with non-clinical control in the cognitive and motor domain of impulsivity and (ii) whether IGD patients have higher cognitive inflexibility compared with nonclinical control in the domain of compulsivity. Our second area of interest in this study was to clarify if IGD patients differ from non-clinical comparison group with respect to the level of impulsivity and compulsivity, and such difference was unique to IGD or shared by individuals with AUD and OCD.

\section{METHODS}

\section{Subjects}

The sample comprised 86 patients with a diagnosis of IGD, 39 with AUD, 23 with OCD, and 77 HC. IGD and AUD patients were recruited from the outpatient clinic of SMGSNU Boramae Medical Center in Seoul, South Korea, where they were being treated for excessive Internet gaming or alcohol use. HC subjects were recruited from the local community; they had no history of psychiatric illness and played Internet games less than $2 \mathrm{hr}$ /day. OCD patients were recruited from the OCD outpatient clinic at the Seoul National University Hospital (SNUH).

All patients with IGD, AUD, and OCD were diagnosed by an experienced psychiatrist according to criteria of the DSM5. Young's Internet Addiction Test (Young, 1998) was used to assess the severity of IGD. Test items are rated on a 5-point scale ranging from 1 (very rarely) to 5 (very frequently). The Korean version of the Alcohol Use Disorder Identification Test (AUDIT-K; Kim et al., 1991) was used to assess the severity of AUD. This scale measures the frequency of alcohol abuse behavior and contains 10 questions, scored on a 4-point Likert scale. Cutoff value for high-risk drinking is above 10 for male and 6 for female (Kim et al., 1991). 
The severity of OCD was assessed with the Yale-Brown Obsessive-Compulsive Scale, a clinical-administered measurement consisting of 10 items (Goodman et al., 1989). Total scores range from 0 to 40, and under 7 are considered subclinical.

Of the 23 OCD patients, 11 were medicated at the time of testing; all were taking a selective serotonin reuptake inhibitor, and one patient was prescribed a small dose of olanzapine $(2.5 \mathrm{mg})$ as an adjuvant. Seven OCD patients were medication-naive, and five patients were medication-free for more than 1 month before entering the study. All patients with IGD and AUD were medication-naive for their lifetime.

The Structured Clinical Interview for DSM-IV (SCIDIV) was administered to identify past and present psychiatric illness in the participants. To measure comorbid depression and anxiety, all patients completed the Beck Depression Inventory (BDI; Beck, Ward, Mendelson, Mock, \& Erbaugh, 1961) and the Beck Anxiety Inventory (BAI; Beck, Epstein, Brown, \& Steer, 1988). The BDI and BAI are 21-item self-reporting questionnaires for evaluating the severity of depression and anxiety based on score range from 0 (not at all) to 3 (severely). In BDI, total score of 0-9 is considered minimal range, $10-18$ is mild, $19-29$ is moderate, and 30-63 is severe. In BAI, total score of 0 9 is considered minimal range, $10-16$ is mild, $17-29$ is moderate, and $30-63$ is severe.

Exclusion criteria included neurological disease; significant head injury accompanied by loss of consciousness; medical illness with documented cognitive sequelae; sensory impairment; or intellectual disability (IQ < 70).

\section{Assessments of impulsivity and compulsivity}

We used the Cambridge Neuropsychological Test Automated Battery (CANTAB), a neuropsychological assessment battery administered by computer using a touch-sensitive screen. It has been used for neuropsychological research across different populations and to study development in the cognitive domain (Luciana \& Nelson, 2002; Roque, Teixeira, Zachi, \& Ventura, 2011). Impulsivity was measured using the stop signal test (SST) from the CANTAB, which assesses the ability to inhibit a prepotent response and impulse control (Logan, Schachar, \& Tannock, 1997). During the task, the participants have to press button by selecting left or right button depending on the direction in which the arrow points. In the second part, an audio stop signal follows in which participants instruct to stop that response. The net direction errors, proportion of successful stops, reaction time on go trials, and stop signal reaction time when quitting the task were used as the dependent variable in this study (see http://www.cambridgecognition/ cantab/).

Compulsivity was assessed by intra-extra dimensional set shift test (IED) from the CANTAB, which measures the ability to shift attentional set. This test examines the ability to inhibit and shift attention between stimulus dimensions (Lawrence, Sahakian, \& Robbins, 1998). In this task, two artificial dimensions of color-filled shapes and white line are presented. Participants must learn which one is correct from two visual stimulus following feedback at each stage, when satisfying six consecutive correct responses. Outcome measures are the number of errors, the number of trials completed, and the number of stages (see http://www.cambridgecognition/cantab/).

Inability to shift attention is an important factor in rigid mental acts and repetitive behavior, leading to an inability to shift attention from a specific thoughts or behavioral set $(\mathrm{Gu}$ et al., 2008). We used the Korean Color-Word Stroop Test (K-CWST; Kim et al., 2004) as a measure of interference control. In the color-word condition, participants are asked to name the ink color of color-words differing from the name of color-words on the presented card as quickly as possible. Therefore, they have to inhibit the automatic process of reading during the K-CSWT. The trail making test (TMT), which assesses motor planning (type A) and cognitive flexibility related to compulsivity (type B) (Reitan, 1992) was also used. The task requires participants to connect a sequence of consecutive targets on a computer screen. TMT-A requires an individual to connect presented numbers as quickly as possible, reflecting visuospatial searching ability. The TMT-B requires a subject to connect the numbers and letters alternately, additionally measuring the ability for cognitive shifting. Total time in seconds for parts A and B and errors (incorrect lines that reach its target) were set as dependent variables (Tombaugh, 2004).

\section{Statistical analysis}

Before the formal analysis, we conducted exploratory data analyses to identify and remove outliers to reduce the possibility of spurious results. We performed analysis of variance (ANOVA) to examine distinct characteristics of the groups. Analysis of covariance (ANCOVA) and Poisson regression were performed to evaluate group differences. We divided variables into continuous and discrete variables. ANCOVA was performed to compare continuous variables, including TMT A/B reaction time and $\mathrm{K}-\mathrm{CWST}$ reading time. Discrete variables, such as TMT A/B error number and K-CWST reading error number were analyzed using Poisson regression. We set age, IQ, depression (BDI), and anxiety (BAI) scores as covariates for ANCOVA and Poisson regression. All statistical analyses were performed using the IBM SPSS software (version 21; IBM Inc., Armonk, NY, USA). $p$ values <.05 were considered to indicate statistical significance.

\section{Ethics}

The study was conducted in accordance with the Declaration of Helsinki. The institutional review boards of SMG-SNU Boramae Medical Center and SNUH approved this study. All participants were informed about the study and provided written informed consent.

\section{RESULTS}

\section{Subject characteristics}

The demographic and clinical/cognitive characteristics of participants are presented in Table 1. No statistically 
Table 1. Baseline demographic and clinical information of subjects

\begin{tabular}{|c|c|c|c|c|c|c|}
\hline & $\begin{array}{c}\text { Internet gaming } \\
\text { disorders }(n=86) \\
\text { Mean }(S D)\end{array}$ & $\begin{array}{c}\text { Alcohol use disorders }(n=39) \\
\text { Mean }(S D)\end{array}$ & $\begin{array}{c}\text { Obsessive-compulsive } \\
\text { disorders }(n=23) \\
\text { Mean }(S D)\end{array}$ & $\begin{array}{l}\text { Healthy controls } \\
\qquad(n=77) \\
\text { Mean }(S D)\end{array}$ & $\chi^{2}$ or $F$ & $p$ \\
\hline Male (\%) & $82(95.35)$ & $32(82.05)$ & $19(82.61)$ & $69(89.61)$ & 6.736 & .058 \\
\hline Female $(\%)$ & $4(4.65)$ & $7(17.95)$ & $4(17.39)$ & $8(10.39)$ & & \\
\hline Age & $21.535(6.906)$ & $28.538(5.409)$ & $23.913(4.552)$ & $22.844(5.671)$ & 12.408 & $<.001 * *$ \\
\hline IQ & $109.870(16.280)$ & $107.308(12.497)$ & $111.304(13.306)$ & 117.703 (9.292) & 6.183 & $<.001 * *$ \\
\hline IAT & $64.821(15.740)$ & $29.750(7.098)$ & $45.111(19.638)$ & $29.026(8.477)$ & 108.664 & $<.001 * *$ \\
\hline AUDIT & $8.605(7.102)$ & $23.861(5.205)$ & $5.375(4.951)$ & $5.410(3.739)$ & 101.753 & $<.001 * *$ \\
\hline Y-BOCS & $0.290(1.512)$ & $0.000(0.000)$ & $22.74(8.950)$ & $0.100(0.403)$ & 126.085 & $<.001 * *$ \\
\hline BDI & $14.413(10.110)$ & $23.250(15.424)$ & $15.500(11.516)$ & $3.959(3.747)$ & 32.792 & $<.001^{* *}$ \\
\hline BAI & $11.797(10.135)$ & $21.861(15.723)$ & $13.278(9.430)$ & $4.880(5.175)$ & 22.365 & $<.001 * *$ \\
\hline
\end{tabular}

Note. Data are given as mean (SD). SD: standard deviation; IQ: intelligence quotient; IAT: Young's Internet Addiction Test; AUDIT: Alcohol Use Disorder Identification Test; Y-BOCS: Yale-Brown Obsessive-Compulsive Scale; BDI: Beck Depression Inventory; BAI: Beck Anxiety Inventory.

$* * p<.01$.

significant difference was observed in gender distribution ( $p=.058$ ) among the four groups, but male participants were prominent in all groups. Clinical/cognitive differences were observed in IGD, AUD, OCD, and HC. The IGD group showed the highest IAT $(p<.001)$ score. The AUD group was oldest $(p<.001)$ and had the highest AUDIT $(p<.001)$, BDI $(p<.001)$, and BAI $(p<.001)$ scores among the four groups. The OCD group showed markedly higher Y-BOCS $(p<.001)$ scores compared with IGD, AUD, and HC. Also, the HC group had the highest IQ $(p<.001)$ scores.

\section{Neurocognitive performance}

Impulsivities in neurocognitive measurements. In the domain of impulsivity, both the IGD and OCD groups made significantly more net direction errors on stop and go trial in the SST (IGD; mean $=3.929 \pm 6.852$, OCD; mean $=4.000 \pm 5.222)$ than did HC (mean $=2.000 \pm$ $3.495)$ after the post-hoc test $(p=.004$ and $p<.001$, respectively). IGD and OCD (IGD; mean $=3.071 \pm 5.544$, OCD; mean $=3.043 \pm 3.902)$ made more direction error compared with $\mathrm{HC}($ mean $=1.493 \pm 2.910)$ on go trials in the SST after the post-hoc test ( $p=.003$ and $p=.001$, respectively). The findings for other groups were inconclusive (Table 2, Figure 1).

Neurocognitive measurement of compulsivity. In the domain of compulsivity, we found that IGD needed more number of total trials to complete IED test (IED total trials) compared with AUD (IGD; mean = 80.635 \pm 19.660 , AUD; mean $=75.943 \pm 11.757 ; p=.007)$ in the post-hoc test with the Bonferroni correction (Table 2, Figure 1).

Completion times and error rate on the TMT part A and B did not vary by diagnostic status (group) (Table 2). In the CWST condition, both IGD and OCD (IGD; mean = $105.470 \pm 21.389, \quad$ OCD; $\quad$ mean $=118.217 \pm 36.478)$ had slower reading time compared with $\mathrm{HC}$ (mean $=94.623 \pm$ 17.826), which requires participants to name the color of word with mismatched ink color in the post-hoc test with the Bonferroni correction ( $p=.004$ and $p=.001$, respectively). In particular, the OCD group showed the slowest reading time in the color-word condition among other groups (Table 2, Figure 1).

\section{DISCUSSION}

This is the first reported study to identify the neurocognitive characteristic of IGD, AUD, and OCD from the perspective of impulsivity and compulsivity. This study showed behavioral abnormalities in both IGD and OCD in relation to impaired response inhibition and cognitive inflexibility. Regarding response inhibition, the IGD and OCD groups showed worst performance than the HC group in the SST with motor and cognitive inhibition. Therefore, our first hypothesis for impulsivity of IGD was supported. Regarding compulsivity, the IGD and OCD groups needed more effort to switch attention in the incongruent color-word condition of Stroop test, reflecting their cognitive inflexibility. This finding supports our second hypothesis for compulsivity of IGD.

Previous studies using the SST have reported impaired response inhibition compared with the control group, suggesting behavioral impulsivity in IGD (Choi, Park, et al., 2014; Ding et al., 2014). A chronic course followed by repetitive relapse in addiction may stem from dysfunctional top-down inhibitory circuitry (Dalley et al., 2011). This impairment may explain why individuals with IGD have difficulty suppressing cravings toward disease-related cue and continue repetitive self-defeating behavior.

An increase in the response time on the K-CWST may result from response competition in a situation demanding that one inhibit the incorrect, but easier, response (Adleman et al., 2002). Many researchers have also used the Strooprelated effect to measure the suppression of prepotent response in substance addiction (Adleman et al., 2002; Goldstein \& Volkow, 2002). Obsessive-compulsive symptoms seen in OCD have been suggested as examples of inhibitory failure or inability to shift attention from these ongoing thoughts or motor activities toward less distressing ones (Greisberg \& McKay, 2003). 
Table 2. Results of neurocognitive tests among the groups

\begin{tabular}{|c|c|c|c|c|c|c|}
\hline & $\begin{array}{c}\text { Internet gaming } \\
\text { disorders } \\
(n=86) \\
\text { Mean }(S D)\end{array}$ & $\begin{array}{l}\text { Alcohol use } \\
\text { disorders } \\
(n=39) \\
\text { Mean }(S D)\end{array}$ & $\begin{array}{c}\text { Obsessive- } \\
\text { compulsive } \\
\text { disorders }(n=23) \\
\text { Mean }(S D)\end{array}$ & $\begin{array}{l}\text { Healthy controls } \\
\qquad(n=77) \\
\text { Mean }(S D)\end{array}$ & $p$ & Post-hoc \\
\hline TMT A (s) & $22.512(7.442)$ & $22.135(6.412)$ & $24.045(10.265)$ & $20.377(6.260)$ & .114 & \\
\hline TMT B (s) & $58.702(26.594)$ & $61.892(23.924)$ & $61.364(31.042)$ & $51.133(12.860)$ & .096 & \\
\hline TMT A error & $0.117(0.512)$ & $0.103(0.384)$ & $0.000(0.000)$ & $0.173(0.476)$ & .751 & \\
\hline TMT B error & $0.571(1.105)$ & $1.308(2.802)$ & $0.200(0.447)$ & $0.453(0.859)$ & .050 & \\
\hline $\begin{array}{l}\text { Stroop color-word } \\
\text { RT (s) }\end{array}$ & $105.470(21.389)$ & 99.865 (18.207) & $118.217(36.478)$ & $94.623(17.826)$ & $.002 * *$ & $\begin{array}{l}\text { IGD }>\text { HC, } \\
\text { OCD }>\text { HC, } \\
\text { OCD }>\text { AUD }\end{array}$ \\
\hline Stroop word RT (s) & $59.061(10.664)$ & $56.083(6.975)$ & 63.783 (20.097) & $54.947(9.272)$ & $.033^{*}$ & n.s. \\
\hline Stroop word error & $0.605(0.939)$ & $0.846(1.755)$ & $0.500(0.837)$ & $0.560(0.858)$ & .603 & \\
\hline $\begin{array}{l}\text { Stroop color-word } \\
\text { error }\end{array}$ & $3.145(3.114)$ & $4.289(14.582)$ & $3.500(2.739)$ & $2.773(2.768)$ & .746 & \\
\hline IED total errors & $9.435(7.058)$ & 11.919 (5.649) & $11.739(7.047)$ & $8.855(6.724)$ & .731 & \\
\hline IED total trials & $80.635(19.660)$ & 75.943 (11.757) & $75.522(15.132)$ & 76.855 (14.996) & $.046^{*}$ & IGD > AUD \\
\hline $\begin{array}{l}\text { SST direction errors } \\
\text { on stop and go } \\
\text { trials }\end{array}$ & $3.929(6.852)$ & $2.622(5.155)$ & $4.000(5.222)$ & $2.000(3.495)$ & $<.001 * *$ & $\begin{array}{c}\text { IGD }>\text { HC, } \\
\text { OCD }>\text { HC, } \\
\text { OCD }>\text { AUD, } \\
\text { IGD }>\text { AUD }\end{array}$ \\
\hline $\begin{array}{l}\text { SST direction errors } \\
\text { on go trials }\end{array}$ & $3.071(5.544)$ & $2.000(4.103)$ & $3.043(3.902)$ & $1.493(2.910)$ & $.007 * *$ & $\begin{array}{l}\text { IGD }>\text { HC, } \\
\text { OCD }>\text { HC, } \\
\text { OCD }>\text { AUD }\end{array}$ \\
\hline $\begin{array}{l}\text { SST proportion of } \\
\text { successful stops } \\
\text { last half }\end{array}$ & $0.500(0.115)$ & $0.520(0.144)$ & $0.497(0.080)$ & $0.524(0.119)$ & .585 & \\
\hline $\begin{array}{l}\text { SST SSRT last } \\
\text { half }(\mathrm{ms})\end{array}$ & $183.330(65.988)$ & $166.530(54.530)$ & $183.330(65.988)$ & $159.669(50.272)$ & .053 & \\
\hline
\end{tabular}

Note. $p$ value was adjusted by age, IQ, BDI, and BAI. SD: standard deviation; TMT A: trail making test A completion time; TMT B: trail making test B completion time; IED: intra-extra dimensional set shift test; Stroop word RT: Stroop word of color-word reading time; Stroop color-word RT: Stroop color of color-word reading time; SST: stop signal test; SST SSRT: stop signal test stop reaction time; IQ: intelligence quotient; BDI: Beck Depression Inventory; BAI: Beck Anxiety Inventory; IGD: Internet gaming disorder; OCD: obsessivecompulsive disorder; AUD: alcohol use disorder; HC: healthy controls.

${ }^{*} p<.05 .{ }^{* *} p<.01$.

Based on evidence from neuroimaging and neuropsychological studies, fronto-striatal dysfunction has been implicated in the pathophysiology of OCD (Menzies et al., 2008; Van den Heuvel et al., 2005). There have been extensive studies on dysfunctional inhibitory control with various measures and paradigms in patients with OCD (Benatti, Dell'Osso, Arici, Hollander, \& Altamura, 2014; Krikorian, Zimmerman, \& Fleck, 2004; Moritz, Kloss, \& Jelinek, 2010). Regarding the Stroop test, prior work suggests that interference control has been shown to be compromised in individuals with OCD, since OCD patients performed worst than controls in inhibitory prefrontal function tests, including the STOP task, GO/NO-GO task, and Stroop task (Penades et al., 2007).

Since cognitive flexibility implies the ability to deautomatize automated responses and to adapt cognitive processing strategies to face new conditions, the Stroop interference effect is related to cognitive inflexibility (Canas, Quesada, Antolí, \& Fajardo, 2003; Moore \& Malinowski, 2009). Taken together, the increased response time on the CWST in IGD and OCD can be regarded as evidence not only for cognitive inflexibility but also of impaired inhibition of interfering stimuli.
In this study, the IGD group showed the worst performance among the four groups in IED total trials, which measures attentional set shifting, in which attention is required to switch between higher-order modalities (Block, Dhanji, Thompson-Tardif, \& Floresco, 2007). As attentional set shifting assesses the ability to adapt behavior flexibly following feedback (Kehagia, Murray, \& Robbins, 2010), this finding indicates persistent damaging behaviors in IGD, which result from a failure to learn new strategies according to the requirements of a given context.

Several studies in SUD have argued that in the course of addiction, initial impulsive use of a drug becomes compulsive drug-taking behavior following neuro-adaptation of striatal circuits, notably shifting from ventral striatal to dorsal striatal hyperactivation (Everitt \& Robbins, 2005, 2013). That is, in the early phase of addiction, individuals initially make risky, but goal-directed, acts to gain immediate pleasure or relief. However, as addiction progresses, the reward effect diminishes, leading to escalating time spent on addictive behaviors. Instead, as compulsive habits develop, stimulus-driven responses can be the driving force toward repetitive behavior (Lubman, Yücel, \& Pantelis, 2004). Individuals with IGD have difficulty ending their gaming 

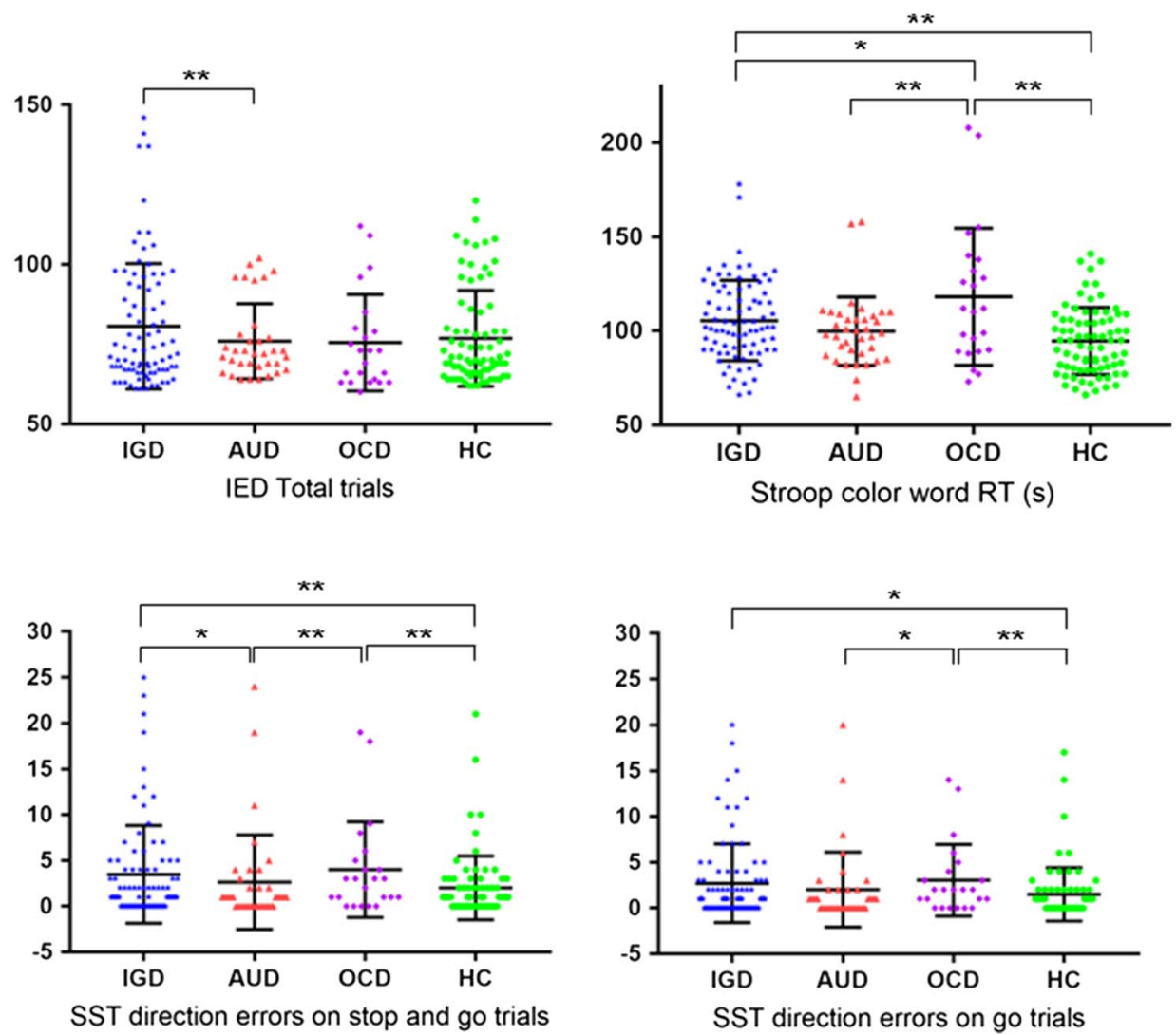

Figure 1. Frequency distribution plots of significant group differences. IGD: Internet gaming disorder; AUD: alcohol use disorder; OCD: obsessive-compulsive disorder; HC: healthy controls; IED: intra-extra dimensional set shift; Stroop color-word RT: stroop color of colorword reading time; SST: the stop-signal test. *Significant difference in the post-hoc test with $p<.05 .{ }^{* *} p<.01$

behavior. Their repetitive action toward gaming-related cues may be explained by their tendency to respond habitually rather than take goal-directed action. Similarly, in OCD, even though stress and anxiety initially lead to the formation of habits, the driving force of compulsive actions may come from habitual and automatic responses rather than expectation of anxiety relief. Consistent with this, one promising treatment modality in OCD is exposure to a conditioned cue (e.g., a bathroom doorknob) and prevention of the subsequent compulsive action, leading to the subject's gaining control over the external stimulus (Whittal, Thordarson, \& McLean, 2005). Thus, in both IGD and OCD, excessive and inflexible behaviors can be explained by stimulus-driven habitual responses with respect to compulsivity.

The OCD and HC groups did not differ significantly in IED total trials. One explanation for this finding could be a medication effect in the OCD group, because manipulation of the serotonergic system can affect cognitive functioning (Meneses, 1999). In this study participants, the OCD group only included 12 patients taking prescribed medications at the time of testing.

This study has several limitations that need to be considered when interpreting the findings. First, the representativeness of the populations may be a concern. In this study, the AUD group did not show clear deficits compared with the control groups in neurocognitive measurements. Second, the sample consisted primarily of male participants. In addition, the medication status of the OCD patients was not controlled in the analysis. Further research should consider include equal proportions of subjects in all groups and greater homogeneity among patient groups.

In this study, we sought to determine commonalities and differences in the neurocognitive characteristics of IGD, AUD, and OCD individuals, all of which show rigid patterns of behavioral repetition associated with significant impairments in function, viewed from the perspective of impulsivity and compulsivity. Our findings indicate that patients with IGD and OCD share underlying deficit in inhibitory control and cognitive shifting. Thus, continuous playing behavior in IGD may reflect difficulty with suppressing cue-initiated responses and responding flexibly to changing conditions.

We conclude that cognitive characteristics of IGD are different in some ways from those in AUD and OCD, but there are also similarities across these conditions. These findings may help in characterizing substance and behavioral addiction more precisely, and in understanding shared neurobiological substrates in addiction and OCD. Initial patient assessment based on measurable neurocognitive characteristics from the impulsivity-compulsivity perspective may offer a more integrated understanding of these disorders rather than a categorical conceptualization based on certain diagnostic criteria. Such findings would help people to understand their problem based on objective neurobiological perspective, and to enter into a specific cognitive-behavioral change strategy. Specific therapeutic interventions such as targeting prepotent motor inhibition for out-of-control behavior, and targeting cognitive 
inflexibility for repetitive behavior would be adapted. There remains a need for further investigations of neurobiological correlates of the relationships between IGD, OCD, and other addictive disorders.

Funding sources: This work was supported by a grant from the National Research Foundation of Korea (Grant No. 2014M3C7A1062894).

Authors' contribution: J-SC was responsible for the study concept and design. Y-JK drafted the manuscript and performed interpretation of data. JAL and SO contributed to statistical analysis of data. SNK, DJK, JEH, and JSK contributed to the acquisition and supervision of data collection. All authors had full access to all the data in the study and take responsibility for the integrity of the data and the accuracy of the data analysis.

Conflict of interest: The authors declare no conflict of interest.

Acknowledgement: The authors would like to thank all of the participants in this study.

\section{REFERENCES}

Aarseth, E., Bean, A. M., Boonen, H., Colder Carras, M., Coulson, M., Das, D., \& Haagsma, M. C. (2017). Scholars' open debate paper on the World Health Organization ICD-11 Gaming Disorder proposal. Journal of Behavioral Addictions, 6(3), 267-270. doi:10.1556/2006.5.2016.088

Adleman, N. E., Menon, V., Blasey, C. M., White, C. D., Warsofsky, I. S., Glover, G. H., \& Reiss, A. L. (2002). A developmental fMRI study of the Stroop color-word task. NeuroImage, 16(1), 61-75. doi:10.1006/nimg.2001.1046

Altman, J., Everitt, B. J., Robbins, T., Glautier, S., Markou, A., Nutt, D., Oretti, R., \& Phillips, G. D. (1996). The biological, social and clinical bases of drug addiction: Commentary and debate. Psychopharmacology, 125(4), 285-345. doi:10.1007/ bf02246016

American Psychiatric Association. (2013). Diagnostic and statistical manual of mental disorders (5th ed.). Washington, DC: American Psychiatric Association.

Beck, A. T., Epstein, N., Brown, G., \& Steer, R. A. (1988). An inventory for measuring clinical anxiety: Psychometric properties. Journal of Consulting and Clinical Psychology, 56(6), 893-897. doi:10.1037//0022-006x.56.6.893

Beck, A. T., Ward, C. H., Mendelson, M., Mock, J., \& Erbaugh, J. (1961). An inventory for measuring depression. Archives of General Psychiatry, 4(6), 561-571. doi:10.1001/archpsyc. 1961.01710120031004

Benatti, B., Dell'Osso, B., Arici, C., Hollander, E., \& Altamura, A. C. (2014). Characterizing impulsivity profile in patients with obsessive-compulsive disorder. International Journal of Psychiatry in Clinical Practice, 18(3), 156-160. doi:10.1007/ 0-387-23370-9_10

Block, A. E., Dhanji, H., Thompson-Tardif, S. F., \& Floresco, S. B. (2007). Thalamic-prefrontal cortical-ventral striatal circuitry mediates dissociable components of strategy set shifting. Cerebral Cortex, 17(7), 1625-1636. doi:10.1093/cercor/bhl073

Bottesi, G., Ghisi, M., Ouimet, A. J., Tira, M. D., \& Sanavio, E. (2015). Compulsivity and impulsivity in pathological gambling: Does a dimensional-transdiagnostic approach add clinical utility to DSM-5 classification? Journal of Gambling Studies, 31(3), 825-847. doi:10.1007/s10899-014-9470-5

Canas, J., Quesada, J., Antolí, A., \& Fajardo, I. (2003). Cognitive flexibility and adaptability to environmental changes in dynamic complex problem-solving tasks. Ergonomics, 46(5), 482-501. doi:10.1080/0014013031000061640

Chamberlain, S. R., Fineberg, N. A., Blackwell, A. D., Robbins, T. W., \& Sahakian, B. J. (2006). Motor inhibition and cognitive flexibility in obsessive-compulsive disorder and trichotillomania. American Journal of Psychiatry, 163(7), 1282-1284. doi:10.1176/appi.ajp.163.7.1282

Choi, J.-S., Park, S. M., Roh, M.-S., Lee, J.-Y., Park, C.-B., Hwang, J. Y., Gwak, A. R., \& Jung, H. Y. (2014). Dysfunctional inhibitory control and impulsivity in Internet addiction. Psychiatry Research, 215(2), 424-428. doi:10.1016/j. psychres.2013.12.001

Choi, S.-W., Kim, H., Kim, G.-Y., Jeon, Y., Park, S., Lee, J.-Y., Jung, H. Y., Sohn, B. K., Choi, J. S., \& Kim, D. J. (2014). Similarities and differences among Internet gaming disorder, gambling disorder and alcohol use disorder: A focus on impulsivity and compulsivity. Journal of Behavioral Addictions, 3(4), 246-253. doi:10.1556/jba.3.2014.4.6

Curatolo, P., Paloscia, C., D'Agati, E., Moavero, R., \& Pasini, A. (2009). The neurobiology of attention deficit/hyperactivity disorder. European Journal of Paediatric Neurology, 13(4), 299-304. doi:10.1016/j.ejpn.2008.06.003

Dalley, J. W., Everitt, B. J., \& Robbins, T. W. (2011). Impulsivity, compulsivity, and top-down cognitive control. Neuron, 69(4), 680-694. doi:10.1016/j.neuron.2011.01.020

Ding, W.-N., Sun, J.-H., Sun, Y.-W., Chen, X., Zhou, Y., Zhuang, Z.-G., Li, L., Zhang, Y., Xu, J. R., \& Du, Y. S. (2014). Trait impulsivity and impaired prefrontal impulse inhibition function in adolescents with Internet gaming addiction revealed by a Go/No-Go fMRI study. Behavioral and Brain Functions, 10(1), 20. doi:10.1186/1744-9081-10-20

Dowling, N. A. (2014). Issues raised by the DSM-5 Internet gaming disorder classification and proposed diagnostic criteria. Addiction, 109(9), 1408-1409. doi:10.1111/add.12554

Everitt, B. J., \& Robbins, T. W. (2005). Neural systems of reinforcement for drug addiction: From actions to habits to compulsion. Nature Neuroscience, 8(11), 1481-1489. doi:10. 1038/nn1579

Everitt, B. J., \& Robbins, T. W. (2013). From the ventral to the dorsal striatum: Devolving views of their roles in drug addiction. Neuroscience and Biobehavioral Reviews, 37(9), 19461954. doi:10.1016/j.neubiorev.2013.02.010

Gillan, C. M., Papmeyer, M., Morein-Zamir, S., Sahakian, B. J., Fineberg, N. A., Robbins, T. W., \& de Wit, S. (2011). Disruption in the balance between goal-directed behavior and habit learning in obsessive-compulsive disorder. The American Journal of Psychiatry, 168(7), 718-726. doi:10.1176/appi. ajp.2011.10071062

Goldstein, R. Z., \& Volkow, N. D. (2002). Drug addiction and its underlying neurobiological basis: Neuroimaging evidence for the involvement of the frontal cortex. The American Journal of 
Psychiatry, 159(10), 1642-1652. doi:10.3410/f.12291956. 13464058

Goodman, W. K., Price, L. H., Rasmussen, S. A., Mazure, C., Fleischmann, R. L., Hill, C. L., \& Charney, D. S. (1989). The Yale-Brown Obsessive Compulsive Scale: I. Development, use, and reliability. Archives of General Psychiatry, 46(11), 1006-1011. doi:10.1001/archpsyc.1989.01810110048007

Grant, J. E., \& Kim, S. W. (2014). Brain circuitry of compulsivity and impulsivity. CNS Spectrums, 19(1), 21-27. doi:10.1017/ s109285291300028x

Greisberg, S., \& McKay, D. (2003). Neuropsychology of obsessive-compulsive disorder: A review and treatment implications. Clinical Psychology Review, 23(1), 95-117. doi:10. 1111/j.2044-8260.1997.tb01226.x

Griffiths, M. D., van Rooij, A. J., Kardefelt-Winther, D., Starcevic, V., Király, O., Pallesen, S., Müller, K., Dreier, M., Carras, M., Prause, N., King, D. L., Aboujaoude, E., Kuss, D. J., Pontes, H. M., Lopez Fernandez, O., Nagygyorgy, K., Achab, S., Billieux, J., Quandt, T., Carbonell, X., Ferguson, C. J., Hoff, R. A., Derevensky, J., Haagsma, M. C., Delfabbro, P., Coulson, M., Hussainm, Z., \& Demetrovics, Z. (2016). Working towards an international consensus on criteria for assessing Internet gaming disorder: A critical commentary on Petry et al. (2014). Addiction, 111(1), 167-175. doi:10.1111/add.13057

Gu, B.-M., Park, J.-Y., Kang, D.-H., Lee, S. J., Yoo, S. Y., Jo, H. J., Choi, C. H., Lee, J. M., \& Kwon, J. S. (2008). Neural correlates of cognitive inflexibility during task-switching in obsessive-compulsive disorder. Brain, 131(1), 155-164. doi:10.1093/brain/awm277

Hyman, S. E. (2007). The neurobiology of addiction: Implications for voluntary control of behavior. The American Journal of Bioethics, 7(1), 8-11. doi:10.1093/oxfordhb/9780199570706. 013.0056

Kehagia, A. A., Murray, G. K., \& Robbins, T. W. (2010). Learning and cognitive flexibility: Frontostriatal function and monoaminergic modulation. Current Opinion in Neurobiology, 20(2), 199-204. doi:10.1016/j.conb.2010.01.007

Kim, K. B., Hahn, K. S., Lee, J. K., Rhee, M. K., Kim, Y. K., \& Kim, C. K. (1991). The preliminary study of the Korean Alcoholism Screening Test (III). Journal of Korean Neuropsychiatric Association, 30(3), 569-581.

Kim, T. Y., Kim, S., Sohn, J. E., Lee, E. A., Yoo, B. G., Lee, S. C., Hong, T. Y., \& Kim, M. J. (2004). Development of the Korean Stroop Test and study of the validity and the reliability. Journal of the Korean Geriatrics Society, 8(4), 233-240.

Király, O., \& Demetrovics, Z. (2017). Inclusion of gaming disorder in ICD has more advantages than disadvantages: Commentary on: Scholars' open debate paper on the World Health Organization ICD-11 gaming disorder proposal (Aarseth et al.). Journal of Behavioral Addictions, 6(3), 1-15. doi:10.1556/ 2006.6.2017.046

Krikorian, R., Zimmerman, M. E., \& Fleck, D. E. (2004). Inhibitory control in obsessive-compulsive disorder. Brain and Cognition, 54(3), 257-259. doi:10.1016/j.bandc.2004.02.038

Lawrence, A. D., Sahakian, B. J., \& Robbins, T. W. (1998). Cognitive functions and corticostriatal circuits: Insights from Huntington's disease. Trends in Cognitive Sciences, 2(10), 379-388. doi:10.1016/s1364-6613(98)01231-5

Logan, G. D., Schachar, R. J., \& Tannock, R. (1997). Impulsivity and inhibitory control. Psychological Science, 8(1), 60-64. doi:10.1111/j.1467-9280.1997.tb00545.x
Lubman, D. I., Yücel, M., \& Pantelis, C. (2004). Addiction, a condition of compulsive behaviour? Neuroimaging and neuropsychological evidence of inhibitory dysregulation. Addiction, 99(12), 1491-1502. doi:10.1111/j.1360-0443. 2004.00808.x

Luciana, M., \& Nelson, C. A. (2002). Assessment of neuropsychological function through use of the Cambridge Neuropsychological Testing Automated Battery: Performance in 4- to 12-year-old children. Developmental Neuropsychology, 22(3), 595-624. doi:10.1207/s15326942dn2203_3

Meneses, A. (1999). 5-HT system and cognition. Neuroscience and Biobehavioral Reviews, 23(8), 1111-1125. doi:10.1016/ s0149-7634(99)00067-6

Menzies, L., Achard, S., Chamberlain, S. R., Fineberg, N., Chen, C.-H., Del Campo, N., Sahakian, B. J., Robbins, T. W., \& Bullmore, E. (2007). Neurocognitive endophenotypes of obsessive-compulsive disorder. Brain, 130(12), 3223-3236. doi:10.1093/brain/awm205

Menzies, L., Chamberlain, S. R., Laird, A. R., Thelen, S. M., Sahakian, B. J., \& Bullmore, E. T. (2008). Integrating evidence from neuroimaging and neuropsychological studies of obsessive-compulsive disorder: The orbitofronto-striatal model revisited. Neuroscience and Biobehavioral Reviews, 32(3), 525-549. doi:10.1016/j.neubiorev.2007.09.005

Moore, A., \& Malinowski, P. (2009). Meditation, mindfulness and cognitive flexibility. Consciousness and Cognition, 18(1), 176-186. doi:10.1016/j.concog.2008.12.008

Moritz, S., Kloss, M., \& Jelinek, L. (2010). Negative priming (cognitive inhibition) in obsessive-compulsive disorder (OCD). Journal of Behavior Therapy and Experimental Psychiatry, 41(1), 1-5. doi:10.1016/j.jbtep.2009.08.004

O'Brien, C. P., Volkow, N., \& Li, T. (2006). What's in a word? Addiction versus dependence in DSM-V. The American Journal of Psychiatry, 163(5), 764-765. doi:10.1176/appi. ajp.163.5.764

Okasha, A., Rafaat, M., Mahallawy, N., Nahas, G. E., Dawla, A., Sayed, M., \& El Kholi, S. (2000). Cognitive dysfunction in obsessive-compulsive disorder. Acta Psychiatrica Scandinavica, 101(4), 281-285. doi:10.1034/j.1600-0447.2000.101 004281.x

Penades, R., Catalan, R., Rubia, K., Andres, S., Salamero, M., \& Gasto, C. (2007). Impaired response inhibition in obsessive compulsive disorder. European Psychiatry, 22(6), 404-410. doi:10.1016/j.eurpsy.2006.05.001

Pontes, H. M., Kiraly, O., Demetrovics, Z., \& Griffiths, M. D. (2014). The conceptualisation and measurement of DSM-5 Internet gaming disorder: The development of the IGD-20 Test. PLoS One, 9(10), e110137. doi:10.1371/journal. pone.0110137

Purcell, R., Maruff, P., Kyrios, M., \& Pantelis, C. (1998). Neuropsychological deficits in obsessive-compulsive disorder: A comparison with unipolar depression, panic disorder, and normal controls. Archives of General Psychiatry, 55(5), 415-423. doi:10.1001/archpsyc.55.5.415

Reitan, R. M. (1992). Trail making test: Manual for administration and scoring. Tucson, AZ: Reitan Neuropsychology Laboratory.

Roque, D. T., Teixeira, R. A. A., Zachi, E. C., \& Ventura, D. F. (2011). The use of the Cambridge Neuropsychological Test Automated Battery (CANTAB) in neuropsychological assessment: Application in Brazilian research with control children 
and adults with neurological disorders. Psychology \& Neuroscience, 4(2), 255-265. doi:10.3922/j.psns.2011.2.011

Starcevic, V., \& Aboujaoude, E. (2017). Internet gaming disorder, obsessive-compulsive disorder, and addiction. Current Addiction Reports, 4(3), 317-322. doi:10.1007/s40429-017-0158-7

Tombaugh, T. N. (2004). Trail Making Test A and B: Normative data stratified by age and education. Archives of Clinical Neuropsychology, 19(2), 203-214. doi:10.1016/S0887-6177 (03)00039-8

Van den Heuvel, O. A., Veltman, D. J., Groenewegen, H. J., Cath, D. C., Van Balkom, A. J., Van Hartskamp, J., Barkhof, F., \& van Dyck, R. (2005). Frontal-striatal dysfunction during planning in obsessive-compulsive disorder. Archives of General Psychiatry, 62(3), 301-309. doi:10.1001/archpsyc.62.3.301

Whittal, M. L., Thordarson, D. S., \& McLean, P. D. (2005). Treatment of obsessive-compulsive disorder: Cognitive behavior therapy vs. exposure and response prevention. Behaviour Research and Therapy, 43(12), 1559-1576. doi:10.1016/j. brat.2004.11.012

Young, K. S. (1998). Internet addiction: The emergence of a new clinical disorder. CyberPsychology \& Behavior, 1(3), 237244. doi:10.1089/cpb.1998.1.237 